his case, or rather, treated himself by medical means only; he having been an assistant to a medical man, and thus having acquired an unfortunate idea that he was competent to manage his own ailments. When he was admitted, the mischief had progressed to such an extent, and the condition of the urethra was such a complication of recent and old mischief, that little hope could be entertained of successful treatment.

CASE II. T. 13., aged 39, was admitted under Mr. Hawkins's care on May 18th. He had had a stricture for about six years near the orifice, the result of an attack of syphilis, in which much of the glans penis had sloughed away, and a new orifice had been formed on its lower aspect. He had never been under treatment for stricture, except once, when a No. 4 silver catheter had been passed into the bladder six times. Four years ago he was at this hospital for retention of urine, when he was relieved after the use of the hot bath, but did not remain in the house. Latterly he had been subject to retention, for a few hours, occasionally; but he had neglected it. On the morning before admission, retention came on, and had persisted up to that time. Just previous to his coming here, he found the penis and scrotum becoming red and enlarged. On admission it was seen that the cellular tissue of the whole penis and scrotum was much infiltrated, and the redness was beginning to show itself it the groins and lower part of the abdomen. There was no pain or hardness in the perinæum, and he gave a distinct history of the effusion having commenced in the penis. The prepuce was so swollen that it was impossible to find the orifice of the urethra, until it had been slit up; and even then it was very difficult to get any instrument into the urethra. At length a small silver catheter was nassed. The stricture near the orifice did not offer much obstacle ; but one was met with lower down, in front of which a false passage seemed to exist, as the catheter went in for some distance without arriving at the bladder. Free incisions were made into all the spots where extravasation existed, and he was ordered to have hot baths to faintness, and large doses of laudanum. After baths in the morning and evening he passed water in drops, but no substantial relief was afforded, although the laudanum was pushed almost to narcotism.

Next day, the gangrene of the scrotum continuing to spread, and the patient's condition becoming constantly worse, a long incision was made in the median line of the scrotum, along its whole length, and carried lown into the urethra. No catheter was put in, but the urine came away from this incision ; not much passed, however, and he still suffered from strangury and pain in passing water. The gangrene continued to extend till it implicated the whole of the scrotum and skin of the penis; and he sank gradually, retaining his senses till the morning of the 23rd, when he became quite comatose, and died in the evening.

On post mortem examination no visceral disease of any im. portance was discovered. The kidneys were healthy, but somewhat congested; the ureters not distended. The whole of the scrotum and penis was one mass of slough, and the urethra terminated anteriorly in a large, sloughing cavity, opening freely into the prepuce. The whole urethra, down to within three inches of the bladder, was much dilated, ragged, and sloughy. About five inches from the glans penis, a stricture existed, in front of which was a false passage leading, for about two inches, into the cellular tissue of the penis. The bladder was much distencled with foul urine, its walls thickened and fasciculated, and its mucous membrane ulcerated in spots, and in some parts of a perfectly black colour from congestion.

Univenstity Coldege Hospital. At a meeting at the hos pital on Wednesday week, Mr. Thomas Field Gibson an nounced that his relative, Mr. George Filliter, of Trigonhill Wareham, Dorset, had sent him $\mathfrak{L} 1,000$ as a donation for the hospital, and had expressed a wish that the amount should be invested, and the income applied in some manner to connect with the hospital the name of his son, Dr. William Filliter, lately deceased at an early age. Dr. Filliter was formerly a distinguished student of the faculty of medicine, and had received his preliminary education in the Junior School and Faculty of Arts of the College. At the same meeting, the committee, having resolved on a former occasion not to have recourse this vear to a public dinner, determined to set on foot a more private appeal for aid towards the year's expenses. Subscriptions towards that object of $\mathfrak{E} 200$ from Mr. J. R. Jaffray and Mr. A. W. Jaffray, father and son, contributors of several like gifts on former occasions, and one of 225 from Mrs. Flanagan (an addition to several former similar gifts for in vestment), were ordered to be inserted in the list of donations.

\section{Gitional Communitations.}

FIVE CASES OF OVARIOTOMY-THREE SUCCESSFUL; WITH PRACTICAL REMARKS.

By I. Baker Brown, Esq., F.R.C.S., Surgeon to the London Home for Surgical Diseases of Women.

[Read before the Harveian Socicty of London.] [Concluded from page 424.]

Case Iv. Ovarian Dropsy, Multilocular; Extirpation; Death, Madame D., aged 35, was admitted into The London Home. on February 19th, 1859. Dr. Grasemann, of Great Russell Street, at whose recommendation she applied to me, has kindly furnished the following history :-

"Madame D. had typhus fever about a year before her marriage, which took place fourteen years since. She has had four children; the last in 1853. During her last pregnancy, she suffered from prolapse of the womb; and after her confinement, was ill for long time with pain in the lower part of her abdomen. About four years ago, a tumour was diagnosed in the hypogastric region by M. Nélaton, of Paris, who is said to have mentioned the right side as its seat. Blisters werc applied, and medicines given; and it is said to have disappeared under this treatment. Two years ago she came to England, and did not perceive any enlargement at that time. After six months, the abdomen began to enlarge again, and was again reduced by treatment. In another six months the enlargement began again, and she went over to Brussels, and was under the care of $M$. Raspail for four months, and afterwards under Messrs. Jolly and Charron. In August 1858, sho was tapped for the first time (on this occasion, Mr. Jolly is said to have pronounced her liver to be diseased). The paracentesis was repeated in six weeks; and again on November 4 th, December 10th, 1858, and January 18th, 1859. Menstruation was regular up to the last."

I saw her in the early part of February; and from the history of the case and a careful examination, I had no difficulty in pronouncing it to be multilocular ovarian tumour; and further, it was certainly a case in which no resource was left except extirpation. I stated very fully the great dangers of the operation; and, after consideration, she elected to undergo it. I ordered her a tonic, as her general health was a good deal reduced. When admitted into The Home, she was very rapidly filling again; and from the great sense of fluctuation, $I$ had no doubt there was a good deal of peritoneal fluid in addition to the ovarian.

After due preparation by warm baths and gentle aperients and tonics, I proceeded to operate, on February 24 th, at 2 I.M., assisted by my colleagues Messrs. Nunn and Philip Harper, as well as by the several visiting surgeons. Mr. Edwards administered chloroform. I made an incision about seven inches long between the umbilicus and pubes, and carefully cut down to the peritoneum, which I then punctured, and let out forty five pints of fluid. The ovarian cyst now appeared: $I$ then passed my hand around it, and found that there were only a few adhesions, but that these were very strong and thick-one especially, which passed up to the edge of the liver. I now punctured the cyst, and let out several pints of thick fluid. It was then easily drawn out of the abdomen. I tore through the smaller adhesions; but the one which passed to the liver and one of the others were so thick, and contained such large vessels, that I passed a twine ligature round them before dividing, and allowed them to return into the abdomen. The pedicle was then drawn out; and, Mr. Philip Harper's clamp being put on, it was fixed in an instant, without the possibility of slipping. I then sponged out the fluid which remained in the abdomen, and closed the opening with iron wire sutures, the pedicle being retained at the lower end of the incision. Wet lint and strips of plaister were put on, a broad flannel bandage was passed around the abdomen, and the patient was replaced in her bed.

3.30 P.xr. The pulse was 100. Two grains of opium were given. Wine and ice were ordered.

10 P.r. The pulse was 120. She had a little sickness. Ono grain of opium was given.

February 26th. She slept a little in the night. She had a little brandy once. Sickness was troublesome.

3.30 P.3r. Pulse 110. The tongue was slightly coated, but 
moist. The skin was moist. She locked unfavourably, and moismuch sickness. She was ordered to take two grains and a hall of calomel, and five grains of Dover's powder every four hours. Igg and brandy, beef-tes, and wine, were given.

February 27 th, 3 s.x. She appeared rapidly sinking, and was pulsoless. Vomiting was incessant. Brandy and beef-tea ras pata were given, and opium suppositories were applied.

8 A.M. She had somewhat rallied. There was no pain, but 8 good deal of swelling of the abdomen. Egg and brandy were ordered to be given, as much as possible.

9 p.dr. She was very low. There was no pain.

February 28th. She was lower; pulse 130. She was ordered to have ten minims of tincture of sesquichloride of iron overy four hours, and in the evening three grains of quinine.

March 1st. She slept a little doring the night, but slightly wandered, and was restless. She was very sick; the romited matter was nearly pure bile. In the latter part of the day, she became very restless, and almost maniacal at night. Dr. Hall Davies saw her, and advised half a drachm of tincture of henbane and a drachm at midnight.

She gradually sank; and died at 4.45 A.x. on March 2nd, six dars after operation.

Post Mortex Examnation twelve hours after death. Pretty firm adhesions of the wound had taken place. The perito. neum was much inflamed; a good deal of lymph had been effused, and glued the intestines together. The ligatures which had been returned into the cavity were surrounded by solid effusion. The liver was rery pale, and so soft in terture ss to break down on the slightest pressure. The kidneys were enlarged, and congested. The heart and lungs were healthy. The uterus was very large and congested. Menstruation was taking place. The vessels in the pedicle were perfectly obliterated by the clamp, and an injection of water could not be forced through them.

Remarks. It is evident that this case was a most unfarourable one for operation; still there was nothing else left to be done; and, in my opinion, the cause of death was the diseased liver: and without any operation she would have pro. bally died after an ordinary tapping.

OAsE v. Ovarian Dropsy in both Ovaries: Multilocular: Extirpation : Cure. I was called to Mrs. W., aged 45, mother of two children, by Mr. Philips, of Pentonville Road, who gave me the following history :-

"About five years ago, Mrs. W. got into ill health; she had a large annular induration over the ala nasi, of a deep brown colour, looking like the beginning of some form of lupus. After some gontle medicine and the occasional application of tincture of iodine, the patch disappeared; but before it had entirely gone a deep seated glandular swelling began to rise from the chest, behind the left clavicle. This swelling increased slowly upwards, and produced some dyspncea by pressure upon the bronchus, It was osteo-sarcomatous in feel, triangular in shape, with its base in the chest, and apparently firmly attached to the adjacent structures. It disappeared rapidly after two or three weeks attention to the general health, and the frequent application of iodine. Soon after its disappearance, she became constantly sick and a good deal emaciated, and complained of excessive pain and pressure in the rectum on going to stool On examining the rectum, the end of the finger just reached a hard nodulated substancs, which seemed to be pressed backFards from the npper part of the vagina. The raginal passage however, was found to be perfeotly free; but at its npper and posterior part, behind the nterns, the same hard nodulated mass could be distinctly felt, and it was exceedingly tender to the tonch, both here and in the rectum. A variety of remedies Were tried for the purpose of relieving the distressing sickness. The liver seemed to be most inactive; and the greatest amoun of relief was, I think, obtained from the measures applied directly to the functions of this organ. After a short interval, I was again summoned to her, and found her much improved in general health, but the abdomen so.swollen, as to press on the diaphragm and impede respiration. It was, I believe, thought that pregnancy had taken place; but the abdomen fluctuated distinctly and the catamenia were regular. I had no difficulty in arriving at a different conclusion. The fluid was evidently encysted, as the patient could lie down quite flat without any increase of dyspnces. About four years ago I first tapped her and withdrew a full house-pail full of stram-coloured fluid, loaded with albumen; apparently nothing but serum. After an interval of fourteen weeks, during which she greatly improved in health, I repeated the operation; and about the same quan tity and quality of fluid came away. At intervals of three or four months she was tapped until about a year ago, since which not more than geven or eight woeks have elapsed between the operations. The character of the fluid changed into a brown coffee colour at the third or fourth operation, then again became pale; and the last seven or eight times has been pale and straw. coloured, as at first, and quite sticky with albumen. She has recovered quickly after each tapping, being generally out in a week or ten days each time. Latterly, since the abdomen has become more rapidly distended, there have been marked emaciation and loss of power; and she feels that she cannot go on much longer without some more permenent form of relief. The urine has never been albuminous; but has varied in quantity according to the state of distension of the abdomen."

I saw her on February 10th,1850, and found the countenance pale and unhealthy, but cheerful and hopeful, and the abdomen rapidly refilling. From the above very succinct history, by Mr. Philips, and her present state, I had no difficulty in arriving at the conclusion that she was suffering from multilocular ovarian dropsy, and that no resource was left except extirpation. This proposition met with the hearty concurrence of the patient, who had already made up her mind to any operation, however full of danger, which might be proposed. I ordered gentle aperients and ten grains of citrate of quinine and iron three times a das, and a warm bath at night.

February 25th, 2 P.M. I proceeded to operate, assisted by Messrs. Nunn and Philip Harper; Messrs. Philips, Ramsbottom, Worthington, and others, being present. Mr. Edwards administered chloroform. I made an incision, about six inches in length, between the umbilicus and pubes, and carefully di. vided the structures down to the peritoneum, which was then opened and sereral pints of fluid were let out. A substance closely resembling a large cauliflower then presented itself, which further examination showed to be a growth attached to a large mass of cells of the right ovary. There were only a few moderate adhesions, which I tore through, and pulled the mass out through the wound. The pedicle was short; the clamp of a pair of calipers was passed around and tightly closed, and the mass of cyst was cut off. This being done, another tumour of the size of a child's head was visible in the left side of the $\mathrm{ab}$. domen. I found it to be a mass of cyst attached to the left ovary. One unexpected difficulty now presented itself. On endeavouring to pass my hand round the mass, to withdraw it, I found it so firmly adherent that I could not move it. Careful examination showed that this did not arise from ordinary ad. hesions; but it appeared as though the mass were entirely surrounded by a layer of pelvic fascia. With a good deal of trouble, I mauaged to insinuate my hand between the cyst-wall and thus succeeded in enucleating the mass, repeatedly upturning cysts, each containing fluid of different colours and density. In three places the union was so complete and intimate that I was obliged to use the ecraseur to divide portions of the adhesions. I was thus enabled to withdraw the mass ; and, having no second clamp, I passed a strong whipcord liga. ture around the pedicle, and bringing it close to the clamp alreadyffastened on the right pedicle, $I$ tied it to one of its blades. I now carefully sponged all the fluid out of the abdomen, and finding no hæmorrhage, I proceeded to close the wound with iron wire sutures, at intervals of balf an inch, and retained the clamp, with both pedicles, at the lower extremity of the incision. Wet lint, with broad strips of adhesive plaster, were put on the incision; a broad flannel bandage was passed around the abdo. men, and the patient was put into bed.

From this time she steadily progressed. The clamp was remored on the seventh day, and each day, one or more sutures. On the eleveuth day the bowels were relieved by enemata, and on the fourteenth day she was removed to the sofa, and is now (March 16th) gradually gaining strength; the whole line of incision is healed, except at the point where the pedicles came out. She eats, drinks, and sleeps well; and her bowels act easily of their own accord.

Remarks. This is the first case I have met with where both ovaries were so diseased as to require extirpation; and when the patient's bad general health is considered, with the length of the disease, the character of the cysts, the double extirpation, extensive adhesions, etc., I think we may fairly say that this case is unique in ovariotomy. It will be seen that the écraseur was used to separate the adhesion. I believe it was the best mode of effecting the object. I need not say that no other mode of treatment was open to ns. The repeated tappings only relieved tomporarily, and death was hastening on very rapidly.

I shall not attempt to draw any comparisons with this and other great operations. We have no proper data to go upon at 
present; but taling these five cases, $T 0$ ses three bives suved that would otherwise have been lost. The reeults of all the operations performed during the past fifteen months in London, shew Inther more than one out of two successful ; and $I$ have no doubt that when the diagnosis of this disease is more perfect; when the operation is performed earlier; when all the steps of the operation are carefully done; when health is improved by diet and medicine before operstion; and when the after treatment is thoroughly understood-then, and not till then, must we expect to be able to lay down any table of com. parison. Let us, however, be encouraged by the experience of herniotomy, lithotomy, and lithotrity, and the more recent amputations of the thigh ; and, observing how improred treat. ment has told upon their statistics, let us confidently anticipate that surgery will yet triumph in ovariotomy, and thus benefit hamanity.

17, Connaught Square, Hyde Park, May 1859.

\section{REMARKS ON DR. INMAN'S PAPER "ON THE INFLUENCE OE VITALITY UPON} SEORETION".

By Jonk Kext Spender, Esq., Surgeon to the Eastern Dispensary, Bath.

I HAve read with considerable interest Dr. Inman's paper in the Joursar of April 30th, "On the Influence of Vitality upon "Secretion". His observations embody much that has probably occurred to the thoughtful physiologist, though perhaps never before put into 80 intelligible and practical a form. But the ques. tion is at once suggested: Is not Dr. Inman confonnding two essentially different processes-active and passive seoretion? Ac. tive secretion is a sign and product of life, and is coincident with the activity of all the other organic processes. Pastive secre. tion is almost entirely physical act, and is independent of nerve-power: nay, it even goes on better when nerve-power is diminished or suspended. It scarcely deserves the name of vital function at all; but $I$ apprehend that it pretty accurately defines that phenomenon of which Dr. Inman has given so many appropriate illustrations.

In true secretion, we have three elements to bear in mindthe blood from which the secretion originally comes; the blood-vessel through which the secretion transudes; and the gland-struoture which is the anatomical instrument for separating and eliminating it. Now, the most ultimate gland structure always possesses the several constituents of mucous membrane; namely, areolar tissue, basement-membrane, and epithelial cells; and the special characters of the different secretions are usually said to depend upon the elective faculty with which these epithelial cells are endowed.

Active secretion being an index of present life and force, the epithelial cells are busy in the work; but the term passive secretion literally expresses the fact that the aqueous portion of the blood, and very little else, simply filters through the blood-vessels and gland-walls; and that vital agency has very little to do with it. For example, increased outaneous perspiration is of two kinds-active, when it accompanies bodily exercise; passive, when it is the effect of exhausting diseases, and the prelude of death itself. In the former case, it is the symbol of angmented finction; in the latter, it is merely that the diminished tone of the capillary walls allows the water of the blood to permeate them. Paralysis of the vasi-motor nerves, or any particular dyscrasia, produces the same result. I lately attended a case wich illustrates this point. A child of seven years old had threatening mesenteric disease : her gkin was cold and dry by day, and covered with profuse passive sweat at night. By alterative and tonic medicines, and regulated diet, constitutional improvement quickly ensued, and the passive 87 eat was stopped; and, in the course of a few weeks, the skin was constanuly moistened with the warm dew of active perspiration.

A so-called diuretic drug may appear to exercise a marked effect in increasing the amount of urine; and, if the organic and inorgenic principles of this socretion are increased in proportion to the aqueous constituent, it is a true instance of accelerated functional activity. But, in hysterical and nerrous persons, who pass a large quantity of nearly colourless urine at a time, the haste with which the water filters through the Malpighian tufts leaves scarcely any time for it to be im. pregnated with the contents of the epithelial cells that line the ariniferous tubes, and which are the agents for imparting to 412 the urine its special oharacters. The act is loss a vital the physical one, and cannot with precision be termed a secreton process at all.

Pathology supplies us with numerous fucts illwatrative of the same distinction. The primary stoges of bronohorthoen, gonorrhces, and diarrhos, have partioular features in common; and the exudative products of these forms of loow inflamma $s$ tion have analogous appearances and qualities; but, if these in- $\vec{\sigma}$ flammations beoome chronic in duration or asthenio in degres, the byperæmia in which thes severally originated is unnaturally prolonged, and this local blood-stesis causes a corresponding $\frac{\sigma}{T}$ change in the nature of the exudations.

It is an old doctrine, that secretion is only form of mole. cular nutrition; the tissue nourished being the epithelial cell, and the nutriment supplied to them that which is ultimately $\rightarrow$ destined to be the secretion itself. This being granted, wo have a right to assume that the influence of innervation is much required for the formation and growth of glend-cells $n \vec{\omega}$ for the ultimate elements of every other animal tissne. Con $t$ sequently, when nerve-force is lessened, gland-cells camno $\frac{O}{3}$ form and grow so rapidly, and the secretional product must bo diminished in an equal ratio. Hence, whenever wo bavo an apparently augmented secretion as the accompaniment or ${ }_{1}-$ result of weakened power, we ought to regard it, not as an ex.-. altation of a physiological act, but rather as a retrogression $N$ into the domain of purely physical processes.

\section{ON TNUNITED RRACTURT}

By W. J. Moore, Esq., H.M. Indian Medical Service, Bombay Establishment ; formerly Senior Resident Surgeon at the Queen's Hospital, Birmingham.

Urress there be some constitutional cause, either already per.0 sistent, or the result of circumstances, as. locality, situation diet, etc., immediately after the accident, it will seldom happen that Nature's reparutive process is insufficient to consolidate sO fractured limb, treated with ordinary care both by attendanf and patient. When such non-consolidation does happen, is must always be regarded as a grave and serious occurrence, ano the more so the nearer the trunk it may be situated. Thuef both as regards the inconvenience to the patient, and the diffis culty and dangers attending attempts at cure or relief, the bones of the forearm or leg will give more anxiety to the suro geon than those of the foot or hand; and, again, in their turn, the tibia, ulna, and radius, are less a cause for nneasiness than when the femur or humerus is the bone affected. This remarf is not only true regarding operative attempts at cure, but applies with double force to those unfortunate cases where the state of the limb requires amputation as a dernier ressort.

The bones in which false joints most frequently occur are of according to the statistics collected by Mr. Norris, those of the thigh and arm (American Journal of the Medical Sciences, rop xxix, 1842); but my own experience rould lead me to infe? that the occurrence took place at least as frequently in the bones of the forearm us in those of any other part of the frame. South (Chelius, p. 888) states that unnatural jointe are most frequent in the upper arm; nezt, the femur would appear to be the one generally affected; and the tibia seem least liable to such result. This is, indeed, what one would, priori, suppose to be the case, as it is evident that a brokes. leg can be kept in perfect apposition with greater ease and ap curity than a broken thigh; and thus one source of unnaturat joint does not act with the same frequency an the formet part.

The causes of non-union of broken bones, and of unnatur and false joints, are numerous; but foremost may be meip tioned a debilitated or cachectic condition of system. Sin Astley Cooper, in his work On Fractures and Dislocations, ${ }_{0}$ 568, observes: "In numerous instances, the failure of vion may be traced to a defective state of the constitutional porrers 'This debility may arise from divers causes, such as bad foods habitual loss of blood, as from hæmorrhoids; residence in the impure localities or underground tenements of crowded citif Malarious atmosphere will also produce condition in whige union is with difficulty obtained. This was exemplifted in the case of a sailor under my care, when in medical charge of the naval station of Bassadore, in the Persian Gulf, where thing disposition to non-union was happily combated by a lengthen course of quinine and wine.

- For an account of Baseadore, we a paper by the author "On th

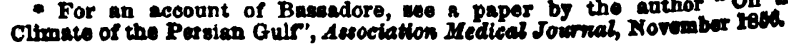

